\title{
A Literature Review: Work, Family and Life - ERA of being a Superwoman Where Women Manage it All
}

\author{
Dr Jai Prakash Tripathi ${ }^{1}$, Ms. Aafreen Roohi Qureshi ${ }^{2}$ \\ ${ }^{I}$ Dean, MBA, Sri Satya Sai University of Technology \& Medical Sciences, Sehore \\ ${ }^{2}$ Sri Satya Sai University of Technology \& Medical Sciences, Sehore
}

\begin{abstract}
Theoretical: Working ladies constitute a basic bit of our workforce and they are required to manage each one of the parts in their lives faultlessly, making a concordance among work and family obligations. Our social set up is still traditional wherein women are fundamentally accountable for home obligations paying little mind to the likelihood that they are contributing out and out to family pay. This survey is an attempt to see how reasonably they juggle each one of these parts and the repercussions on their prosperity, effectiveness, family duties, et cetera. Moreover, the distinctive components adding to keep up a strong work life modify are considered by various researchers.
\end{abstract}

Keywords: Work Life Balance, Multiple role balance, Work Life Conflict of working women.

\section{Presentation}

In a present meeting on the world observed Oprah Winfrey's show "Oprah's Next Chapter", Sheryl Sandberg, at present Chief Operating Officer of Facebook, having held respected positions like Vice President of Google and head of staff for U.S. Agency of the Treasury examined the frustrates of being a productive delegate close by being a working mother. She says "Having everything" is a dangerous expression for women. "Having everything is the most exceedingly dreadful," she tells Oprah. "Not with standing the sum we overall have and how grateful we are for what we have, no one has it all, since we in general make tradeoffs every last day, every last minute."

We in general have keep running over conditions in life when we have to juggle between work obligations and individual obligation or fight to find time for unwinding practices due to work weights. Ever understand concentrated on in light of the way that you couldn't make it to your nearest partner's wedding, or you missed your tyke's yearly limit at school therefore of interminable work due dates? Do you feel sorry eventually of time that you have not been committing enough time to your family and prosperity on account of as far as possible among work and home? Right when the last time you took some time was off and fulfilled something just for yourself? If you have a positive response to any of these requests, you need to keep up a sound Work-Life Balance in your life by having a fitting perception of your needs and reason until the end of time.

Work-life conform, in its broadest sense, is described as an alluring level of incorporation or "fit" between the various parts in a man's life (Hudson, 2005). Work Life change has reliably been a stress of those motivated by the way of working life and its association with broader individual fulfillment (Guest, 2002). The verbalization of work and life, give a part as work-life change, has transformed into a key component of much current government, expert and academic open consideration (Eikhob, Warhurt and Haunschild, 2007). It is assumed that modifying a compelling employment with an individual or family life can test and impact on a man's satisfaction in their work and individual life's parts (Broers, 2005). Dundas(2008) fights that Work Life conform is about sufficiently managing the juggling exhibition between paid work and all extraordinary activities that key to people, for instance, family, bunch works out, think works, self-change and unwinding and diversion. Greenhaus, Collins and Shaw (2003) describe work-life alter as how much an individual is comparatively possessed with - and also content with - his or her work part and family part. In this way, delegates who experience high work-life alters are the people who demonstrate equivalent theory of time and duty, to work and non-work spaces (Virick, Lily and Casper, 2007).

Significance of the survey: It is by and large seen that agents who finish a work-life change that suits them work more capably, are more devoted to their directors and are less disposed to wind up particularly tired in this manner of stress. It in like manner aides in rapidly and dependably makes more regard and conforms every day for the individual. It also helps in driving individual obligation and duty to the affiliation, giving more conspicuous occupation satisfaction, advancement potential and manager security, in this way giving more unmistakable various leveled efficiency. It grows gainfulness at the progressive level. It realizes lessened truancy through decreasing work-family battle; and unequivocally influence on the affiliation's photo as observed by the general populace. A failure to address work-family conflicts has negative impacts not simply 
on the business openings and work quality, prosperity and effectiveness of the workers concerned, moreover on their families, kids and adults alike, both in made and making countries.

Degree of the audit: Work-life alters methodologies and practices can help all people, not just women or those with energetic children. They help people who are accountable for the care of elderly watchmen, people who have contemplate obligations, those more prepared specialists who basically need to guide themselves into retirement or people with other individual and lifestyle obligations.

\section{Audit of Literature}

Supriti Dubey, Ruchi Saxena and Neetu Bajpai (2010) in their audit Work Life Balance: Can Women is Both Bearer and Manager has communicated that a productive work life modifies helps in achieving individual and what's more capable targets of a man. The method for work has changed as before it was viewed as need to survive yet now it is a wellspring of individual satisfaction for delegates. Work Life Balance makes sound agreeable vitality in the work environment of an affiliation and its most basic asset i.e. agents. A sound way of life is the time when we can commit enough time to all circles of life and carelessness none of them. Affiliations need to make cordial conditions in which agents can alter work with their own particular needs and wishes. Relative attempts from family are moreover appealing. It was poor down that components like age, working environment, get ready projects, coincidental points of interest and family reinforce have quantifiably colossal relationship with Work Life Balance of female agents. Respondents who were more than 40 years of age could alter work and life much better than their more young accomplices. It was furthermore watched that energizing work environment in a general sense impacts the ability to make an unrivaled work life alter. Recommendations like sharing the stack, time organization, correspondence with chief and associates and having a positive approach were given to help in a predominant change.

Dr. B. Aiswarya and G. Ramasundaram (2011) in their survey on Working Hours as an Influencing Factor towards Work Family Conflict of women agents in IT Sector in Chennai City pointed out that there is a prompt comparing relationship between the working hours and the Work Life Balance. Out of the case size of 598 respondents, lion's share of the high conflict piece included respondents who work ten hours for every day while not a lot of respondents who work eight hours for consistently were found to have high conflict. The audit was coordinated on women agents in IT portion and it shows a wide cleft between Work Life Conflict levels of females who work for 8 hours and the people who work for 10 hours.

Dr. Navjot Kaur and Parminder Walia (2010) in their survey Emotional Intelligence as a Factor in Creating work Life Balance found that Emotional Intelligence of IT Professionals was seen to be inside and out and unequivocally associated with Personal Life Interference with work $(\mathrm{r}=0.28)$, Work Personal Life redesign $(\mathrm{r}=0.26)$ and general Work Life Balance $(\mathrm{r}=0.25)$ at 0.1 level of centrality. Scores of Emotional Intelligence reach out in the region of 91 and 171 while mean score of EI was 131.57. Scores of work Life Balance stretched out in the region of 48 and 105 while mean was 70.77 . Genuinely astute individuals can successfully adjust up to stressors in individual and work life and along these lines they can restrain hindrance of individual life in work. Individuals with high Emotional Intelligence are better connected with, look for after destinations dependably, they every once in a while lose their cool and are more dealt with. The audit demonstrates that authentically vigilant people tend to make a prevalent work life change and augmentation the proficiency and furthermore the ability to adjust in all conditions of agents.

A Study on Work Life Conflict and Flexible Work Arrangements that Aid Work Life Balance: Perception of Working Women in Dual Career Families by Uma Seshadri and Debendra Kar (2012) included amassing of supposition of working women in twofold job families on work life conform elements and support required from organizations. It assumed that working women see that various leveled approaches that progress versatile work strategies have positive direct association with work life modify. In this way, time flexibility is the most fundamental variable considered by women agents to modify their work and family life. Particularly the going with components affected this acknowledgment: ability to barge in on office work to go to family matters and return to work, ability to coordinate an invaluable work schedule, plan to work not completely from home, course of action of leave when required, game plan of child care and also elderly care workplaces, etc.an overwhelming $93 \%$ of the respondents agreed that they would endeavor to manage both work and family while $88.6 \%$ said they would wouldn't worry putting more vitality in fulfilling family's commitments, thusly indicating importance of family in women's lives. A bigger piece of women (90\% of respondents) exhibited that they envision that support from affiliations will give them approval to go to bleeding edge courses/get-togethers, et cetera, prescribing intense inclination to reliably push their knowledge and aptitude set. In like manner, the survey raise that legitimate support is to a great degree huge in choosing openings for work and in achieving a fancied level of work life conform.

P. Kavitha, Dr. V. Kavitha and P. Arulmurugan (2012) in their survey on Role Of Stress Among 
Women Employees Forming Majority Workforce At IT Sector in Chennai and Coimbatore, Tier I and Tier II centers assumed that women specialists in IT Sector are experiencing high Organizational Role Stress . Colossal complexity was seen between hitched (mean score of 9.14) and unmarried females (mean score of 6.59) on Inter Role Distance i.e. battle among definitive and non-various leveled parts, especially germane for twofold work couples. For whatever period of time that one individual from family stays at home to manage family, InterRole Conflict is required to be less. Hitched women have also shown more Role Expectation Conflict than unmarried women as married women overall respond to a more prominent course of action of tremendous others i.e. conflicting cravings and demands by different part senders. Hitched females in like manner uncovered higher stress as a result of Role Overload i.e. an abundance of is ordinary from the part than they can adjust to. Furthermore, the survey demonstrates that Resource Inadequacy has ascended as the most solid stressor which infers non-availability of benefits required for convincing execution of the part. The mean score for Resource insufficiency was 9.66 trailed by Role Overload (mean score of 9.57) and Personal Inadequacy (mean score of 8.71).

Leena B. Dam and Sudhir Daphtardar (2012) in their audit on Work Life Balance by Women Faculty Members: The Conundrum Within made an attempt to assess the Work Life Balance of representatives in Management Colleges in Pune and found that a bigger piece of women workers imagine that its difficult to modify work and life. The stress from occupation flood in their own life and it is hard to require out speculation for self headway and activities of self premium. Moreover, it has extraordinary impact on their physical and mental wellbeing. Working past the official working hours and putting an overabundance of vitality in family errands in like manner aggravates the thin line of congruity among work and life, as females are all things considered more responsible for tyke mind, elderly care and family obligations. Moreover, the time taken to go to the workplace has been represented by $89 \%$ of respondents to be a vital inhibitor to work life alters. Task canny difference was moreover considered in the distinctive parameters of work life change, it was contemplated that higher task respondents had essentially more need to enlarge commitment hours. Cut down task representatives put most extraordinary vitality in arranging address (45\% of respondents agree to this) while higher task people put most prominent time in educating (half respondents agree to this), while slightest time was spent on understudies' wander related work among all assignments.

Jean E Wallace (1999) in the audit Work-to- Non work Conflict among Married Male and Female Lawyers investigated distinctive segments related to work which add to time-based and strain-based work to non-work battle among married female and male lawyers. Three essential issue considered for this audit were Work Involvement, Work Role Stressors and Work Context. It was found that Work Overload was the sole basic provider to work - non work battle for both male and female lawful counselors. For male lawful counsels, supporters to work- non work battle were absolutely exceptional as working for longer hours; working with firms having more women; and their accessory being the genuine wellspring of wage i.e. associate being bread laborer had affect on work- non work strife when stood out from females being impacted by Work Context as they uncovered higher work- non work battle if they joined a law office versus other law business openings. In like manner, females needed to work in firms having more number of female lawyers. Nearby status components like preschool adolescents and working status of associate had little effect on females' work- non work strife as their strain based conflict was reduced by additional family parts.

Lindsay A. Martin (2012) in her audit Multiple Role Balance, Professional Quality Of Life, And Wellness among Women Employed As Professional Counselors assessed whether there exists a relationship between factors like Multiple Role conform, Number of wards, Professional Quality of Life, Age, Experience and Wellness among women capable teachers as they face peril of Compassion depletion, Burnout and Secondary Traumatic Stress in light of nature of their work being truly asking. Data Analysis revealed that the Mean Total Wellness scores were high (81.13) with possible scores going between 25-100, Mean Multiple Role change was immediate (25.13) with possible extent of 8-40, Professional Quality of Life was incredible, with High Mean Compassion Satisfaction (41.61, with scores between 5-50), Low Mean Burnout (20.71, with scores between 5-50) and low Secondary Traumatic Stress (19.17, with scores between 5-50). The audit certified that a woman's general prosperity level if basically impacted by a higher score on having the ability to viably modify distinctive parts for the duration of her life. $77 \%$ of respondents had coordinate Multiple Role Balance scores, $18 \%$ had high MRB while only $4 \%$ had low MRB exhibiting that larger part women could modify different parts for the duration of their life. Regardless, coordinate Multiple Role Balance could be deciphered in various ways, it might imply that women just recognize their distinctive parts rather than feeling positive about it, they might be content with various parts as they feel they are accountable for them. The results exhibit that Professional Quality of Life and measurement considers in like manner had immense relationship with general prosperity yet number of wards did not impact wellbeing levels. Furthermore, the survey highlights that both individual life and master life should be considered while exploring $\mathrm{n}$ evaluating general sweeping wellbeing. (Capella University, Dissertation, Doctorate of judiciousness, UMI Number 3509173, Proquest, May 2012, UMI Dissertation Publishing). 
Elizabeth Krymis (2011) in her audit Women and Work Life Balance: A Phenomenological Qualitative Analysis of Identity, Relational Style, Adaptive Style, and Drive and Motivation, and the Role of Faith from the Narrative Life Story Framework found that women, who regard and place stock in certainty, interface it to work segment as well. Such women assume that such work is an explanation behind their life set by god; thusly their work is basically critical to them. These women exceedingly regard capable and singular lives and values are an essential bit of adjusting philosophies for them. The audit in like manner found that social establishment and social character also influence experiences and hardships defied by women. In like manner, certainty helped women to grasp their work and individual life in a significantly enhanced way. Women moreover conceded that having distinctive parts decidedly influenced both work and family; a couple of segments of individual life, for example: being a mother impacts a couple parts of work life and diverse parts of being a livelihood organized woman impact singular life unequivocally. As showed by most of the surveys on Work Life Balance, Flexibility was thought to be the most basic segment for finishing a strong Work Life modify. Women said they looked for having their own specific business to finish flexibility; they in a perfect world required a versatile work routine at work with a particular true objective to accomplish a predominant work life Balance. Another basic component was the sentiment acting actually subordinate in all parts of life felt through calling women, which gives them a conclusion joy. It was thusly assumed that certainty is a crucial consider finishing Work Life Balance, in picking the field of calling and it similarly accept a key part observing somebody for women. Certainty moreover impacted their Adaptive Style i.e. how they adjust up to change and it moreover was a figure picking where they might need to contribute their vitality.

Melissa K. Byington (2010) in her survey Principal Balance: Life Role Balance among Women in Secondary School Administration focused the distinctive perspectives of female assistant school administrators on the most capable strategy to modify various parts in life and the difficulties and social obstacles they stand up to in doing similarly. A mind blowing $71 \%$ of respondents agreed that their work obligations interfered with home obligations and a desolate $41 \%$ agreed that home duties strife with work commitments. $55 \%$ couldn't resist negating the declaration that home duties intrude with work obligations. Shockingly $70 \%$ of respondents agreed that the region in which they are working support them to have a perfect work life conform and $73 \%$ feel that they are maintained by their boss. $77 \%$ agree that they have genuine commitments at home and childcare and $65 \%$ agree that another adult at home bestows these commitments to them. Only $43 \%$ of respondents agreed that they had a strong life conform and 35\% couldn't resist repudiating this. Despite the way that an overwhelming some portion of $64 \%$ of respondents feels they can counsel between their various parts, still a lion's share of respondents i.e. $78 \%$ feels that conflicting diverse parts makes stress in their lives. Only $45 \%$ of respondents feel that they are extraordinary at altering different parts while $42 \%$ trust they are awful at it. As to effect of weight on prosperity, $71 \%$ agreed that stress developing of various part asks for impacts their prosperity and $80 \%$ agreed that such nervousness affected their family and individual life. In spite of what may be normal, only $38 \%$ agreed that it impacted their work execution. The women conceded that it was an extraordinary and testing undertaking to fulfill an alter and some even let it out being a weakness for them while others were trying to achieve it by new adjusting frameworks.

Kerri Health (2012) in her audit Women in Leadership: Strategies for Work-Life Balance has driven a phenomenological study among 22 women pioneers using a record life-course structure made by Giele. It was found that critical and fulfilling callings helped women in managing diverse parts and making a positive congruity among work and life. 96 techniques ascended out of the audit and they were accumulated into 18 themes. The most basic procedure was to find critical work, trailed by the second subject which was to 'Procure a Mentor' as these aides help, support and goad in striking the right modify. Other basic themes were to 'Lock in' i.e. being engaged and productive; "Sort out" i.e. to arrange basic family events early guaranteeing they don't strife with work obligations; 'Increase Confidence' i.e. to confide in oneself; "Certainty" i.e. being religious helped them adjust to stretch; 'Candidly steady system' i.e. being maintained by partner, more removed family, associate, outsourcing for childcare and elderly care, et cetera ; 'Work Life Balance Philosophy' i.e. giving up faultlessness and moving toward gradually and deliberately; 'Intentional Parenting'; 'Self care, Play Hard and Hobbies' ; 'Work Strategies takes after work from home, et cetera ; 'Region of work to School/Home' ; "Advancement" ; 'Break from Work'; and 'Regulating sentiments'. Adjusting frameworks contrast from woman to woman and there are diverse sub-points under the already said wide subjects.

Susan Elizabeth Mangels (2008) in her survey Does Balance Matter? The Relationship between Worklife Balance and Success for Women College Presidents drove a learn at private and open foundations in U.S. to find the relationship between Work life Balance and Success of Women as College Presidents. It was found that there is vital relationship between Work Life Balance and presidential accomplishment and the Presidents' period of life furthermore affected his/her flourishing (Work Life Balance without battle/clamor and time of life of presidents cleared up $43 \%$ variance in achievement of presidents). In any case, the audit does not reveal or describe what is suggested by the right time of life for an impeccable alter, neither does it clear up what should be there for Work Life Balance, rather it satisfies what should not be there i.e. nonappearance of dispute and 
dissonance. No of years in organization i.e. residency also affected their success levels. Moreover, Work life conform is up close and personal and everyone has interchange perspectives and desires in life so female presidents should evaluate their business ways and destinations at standard breaks of time remembering the ultimate objective to survey alter in their lives. The perfect time of life insinuates the way that women should think about their advancement level, capacities and aptitudes to go up against an organization work and that the occupation is in fit with their own particular obligations.

Parminder Walia (2011) in her proposition on Work Life Balance of Working Professionals-A Study of IT and ITES Industry examined the relationship between Individual related components (Emotional Intelligence, Work Centrality, Age, Gender and Marital Status), Family related elements (Household Responsibility, Spouse Support and Parental Demands) and Work related variables (Task Variety, Task Autonomy and Work Schedule Flexibility) and general Work Life Balance. The Work Life Balance scores could move between 15 to 105 and the genuine scores of IT and ITES Professionals varied between 48 to 105 . The Average Work Life Balance score was 70.77 and Median score was 70.50. It was found that the mean work life modify was superior to expected for IT and ITES Professionals. Eager Intelligence $(r=0.25)$, Work Centrality $(r=0.20)$, Gender $(r=-0.13)$, Spouse Support $(r=0.29)$ Task Variety $(r=0.21)$ Task Autonomy $(r=$ $0.38)$ and Work Schedule Flexibility $(r=0.17)$ were seen to be decidedly related with Work Life Balance with $r$ qualities being immense. Higher the EI, higher is Work Life Balance, higher is the Work/Personal Life Enhancement and lesser is the block of Personal Life with work and the a different way. Also, women exhibited more Interference of Work with Personal Life when diverged from men. In any case, shockingly there was no tremendous relationship between Number of adolescents, Age, Household obligation, Marital Status and the Work Life Balance of It and ITES Professionals. It was communicated that women select satisfaction and joy from an opinion parenthood, so it doesn't impact their Work Life Balance.

Saroj Parasuraman and Claire A. Stews (2001) in their audit Type of Employment, Work-Family Conflict and Well-Being: A Comparative Study did a first of its kind close examination of the relationship between work part qualities and weights, family part properties and weights, work-family battle, and pointers of success for autonomously utilized individuals versus individuals used in affiliations. It was found that business sort $(\mathrm{F}=10.53, \mathrm{p}<0.001)$ and sexual introduction $((\mathrm{F}=11, \mathrm{p}<0.001)$ had essential impact on the above communicated elements. It was surmised that freely utilized individuals had a great time more self-govern (Mean 4.47 when diverged from mean 3.61), greater flexibility of logbook (Mean 0.20 when appeared differently in relation to mean 0.06) and more raised measures of commitment (Mean 3.09 when stood out from mean 2.45) in their work when diverged from individuals used in affiliations. Shockingly, autonomously utilized individuals uncovered more essential work-family battle, more noticeable family part weights due to parental solicitations, work satisfaction, however cut down satisfaction from family when stood out from definitively used individuals. The reason behind the same is that autonomously utilized individuals commit extra time and obligation to fill in as the commitment with respect to business is solely on their shoulders. Women declared less freedom, less work affiliation, less time obligation to work, less work family strife and less occupation satisfaction(Means 3.75, 2.47, 2.97, 2.69 and 3.59 independently) when diverged from men $(3.93,2.76,3.74,2.86$ and 3.78 exclusively). Women indicated more timetable flexibility (mean $=0.08$ versus 0.07 ), family commitment (mean $=4.17$ versus 3.89 ), time obligation to home (mean $=2.27$ versus 1.64 ) and life extend (mean $=2.93$ versus 2.73 ) than men. The possible clarification behind the same could be that women are more devoted to home and contribute more vitality with family while men need to contribute time with family however can't do thusly. However, women encounter the evil impacts of life stress more than men in light of the different part demands of work and family.

\section{Conclusion}

An extensive measure of research has been finished on the subject of whether women can keep up a sound work life conform and how they end up juggling different parts in life, every so often sidelining their own specific prosperity and individual interests in life. The surveys cover generally every one of the parts of work life change issues that women face. An essential research cleft to be seen here is that work to non work strife has been considered yet the effect of non work to work battle has on a very basic level been disregarded. Also, more all around research about consequences of darkened lines among home and work on the mental and physical soundness of women is required a far reaching point of view of impact of a positive or negative work life modify.

\section{References}

[1] Saroj Parasuraman and Claire A. Simmers (2001), "Type of Employment, Work-Family Conflict and Well-Being: A Comparative Study", Journal of Organizational Behavior, Vol 22, No.5, pp 231-245 
[2] Parminder Walia (2011), "Work Life Balance of Working Professionals- A Study of IT \& ITES Industry”, India

[3] Kerri Health (2012), "Women in Leadership: Strategies for Work-Life Balance”, Dissertation, UMI Number: 3525746, USA

[4] Melissa K. Byington (2010),"Principal Balance: Life Role Balance among Women in Secondary School Administration" UMI Number: 3428254, UMI Dissertation Publishing, Nebraska)

[5] Cho, H. (2006),"Keeping your balance - Experts say workers are on their own juggling jobs, lives", The Baltimore Sun, 1D.

[6] Leena B. Dam and Sudhir Daphtardar (2012), "Work Life Balance by Women Faculty Members: The Conundrum Within", Parikalpana-KIIT Journal of Mgt, Vol-8, pp55 to 67

[7] Jean E Wallace (1999), “Work-to-Nonwork Conflict among Married Male and Female Lawyers", Journal of Organizational Behavior, Vol. 20, No. 6, pp. 797-816

[8] Uma Seshadri and Debendra Kar (2012), "Work Life Conflict and Flexible Work Arrangements that Aid Work Life Balance: Perception of Working Women in Dual Career Families", Prerana, pp 23 to 31

[9] P. Kavitha, Dr. V. Kavitha and P. Arulmurugan (2012), "Role Of Stress Among Women Employees Forming Majority Workforce At IT Sector in Chennai and Coimbatore, Tier I and Tier II centres”, Sona Global Management Review, Vol 6, Issue 3, pp 1-10

[10] Dr. B. Aiswarya and G. Ramasundaram (2011), "Working Hours as an Influencing Factor towards Work Family Conflict of women employees in IT Sector in Chennai City", Tecnia Journal of Management Studies, Vol.6 No. 2, pp 35 - 39

[11] Dr. Navjot Kaur and Parminder Walia (2010), "Emotional Intelligence as a Factor in Creating work Life Balance", Indian Management Studies Journal 14, pp 43-53

[12] Elizabeth Krymis (2011), “Women and Work Life Balance: A Phenomenological Qualitative Analysis of Identity, Relational Style Adaptive Style, and Drive and Motivation, and the Role of Faith from the Narrative Life Story Framework", UMI Number 3481267, UMI Dissertation Publishing, USA.

[13] Global Journal of Management and Business Studies. ISSN 2248-9878 Volume 3, Number 10 (2013), pp. $1187-1196$ 